\title{
The Mediating Effect of Childcare Teacher's Job Stress on the Relationship Between Stress Mindset and Turnover Intention
}

\author{
Minju Koo, Yeoul Shin, Daeun Park \\ Department of Child Welfare, Chungbuk National University, Cheongju, Korea \\ 보육교사의 스트레스 마인드셋과 이직의도와의 관계에서 \\ 직무스트레스의 매개효과 \\ 구민주, 신여울, 박다은 \\ 충북대학교 아동복지학과
}

Objectives: The current study examined the relations between stress mindset, job stress, and turnover intention among childcare teachers $(N=97)$. Some teachers perceived stress as strictly harmful while others perceived it as having possible benefits.

Methods: In a cross-sectional study, 97 childcare teachers completed an online survey. SPSS 22.0 and PROCESS macro were used to test the mediating effect of job stress on the relationship between teachers' stress mindset and turnover intention.

Results: Teachers with a higher perception of stress as having possible benefits tended to experience lower levels of job stress, which in turn led to lower turnover intention. In contrast, teachers with a higher perception of stress as debilitating tended to experience higher levels of job stress, which in turn, predicted greater turnover intention.

Conclusion: The findings suggest that changing the way teachers think about the effects of stress may mitigate their job stress and increase teacher retention.

Keywords: childcare teacher, stress mindset, turnover intention, job stress$$
\text { 서론 }
$$

유아가 보육 시설에서 보내는 시간이 증가함에 따라, 보육의 질 향상에 대한 부모의 요구수준과 기대 또한 높아지고 있다 (Ministry of Health and Welfare [MOHW], 2017). 보육의 질에 영향을 미치는 요인을 살펴보면, 보육교사의 자질(B.-N. Kim, Kwon, Kim, \& Han, 2015)과 전문성(S. J. Kim \& Kim, 2011), 원장의 전문성(C.-H. Kim, Mun, \& Park, 2013)과 리더십(C.-H. Kim et al., 2013), 안전(Lim, 2012), 위생(Lim, 2012), 프로그램

Corresponding Author: Daeun Park, Department of Child Welfare, Chungbuk National University, Chungdae-ro 1, Seowon-Gu, Cheongju, Korean

E-mail: daeun@chungbuk.ac.kr
\end{abstract}

의 질(B.-N. Kim et al., 2015), 시설환경(Rhee, 2014), 교사-부모 상호작용이 있다(Noh, 2012; S.-Y. Son, Im, \& Nam, 2015). 그 중 보육의 질에 영향을 미치는 가장 중요한 요인은 보육교사 와 관련된 요인이다(Choi, 2002; Hong, 2002; K.-S. Pyo \& Lee, 2002). 유아와 함께 하는 시간동안 보육교사는 부모를 대리하 여 보호자와 양육자의 역할을 수행하며, 유아의 발달에 지대 한 영향을 미친다. 또한 수업을 계획하고 운영하는 교육자의 역할뿐 아니라 학급운영, 행정업무, 학부모와의 관계 등 포괄 적서비스를 제공하는 전문가로써 보육의 질을 결정하는 중요

(C)The Korean Association of Child Studies

This is an Open Access article distributed under the terms of the Creative Commons Attribution Non-Commercial License (http:// creativecommons.org/licenses/by-nc/4.0) which permits unrestricted noncommercial use, distribution, and reproduction in any medium, provided the original work is properly cited. 
한 역할을 한다(Huh \& Park, 2010).

보육교사가 보육의 질에 영향을 미치는 중요한 요인임에도 불구하고, 보육교사의 이직은 타 직종에 비해 매우 높다. 2014 년에는 보육기관에 종사하는 보육교사의 이직률이 $24 \%$ 로 나 타났으며, 2015 년에는 $75.5 \%$ 의 어린이집에서 보육교사의 이직 으로 인한 신규교사 채용이 이루어졌다(Ministry of Health and Welfare [MOHW], 2016). 보육교사의 이직은 개인, 기관 및 사 회적 손실을 야기한다(So, 1998). 개인에게는 새로운 환경에 적 응함에 있어 심리적, 신체적 피로감을 증가시키고(S.-M. Kwon, 2011), 보육기관에서는 새로운 교사를 채용하고 교육시키는데 시간과 비용을 투자해야 하며, 남은 교사들의 경우 기존의 팀 워크가 무너지고 사기가 저하된다(H. Yoo, 2011; Whitebook \& Sakai, 2003). 무엇보다 교사의 잦은 이직은 보육의 질 저하로 이어져(K.-S. Pyo \& Hwang, 2011) 영유아의 신뢰감, 정서적 안 정, 대상관계 등 발달 전반에 부정적인 영향을 미친다(Cassidy, Lower, Kintner-Duffy, Hegde, \& Shim, 2011; K. Yoon \& Ji, 2011).

또한 실제 이직을 하지 않았더라도 $27.1 \%$ 의 보육교사가 이 직할 의도가 있는 것으로 나타났다(MOHW, 2013). 보육교사 의 이직의도란 새로운 직장을 계획하거나 탐색하는 등 근무 하는 어린이집을 떠나려는 행위, 즉 이직을 고려하는 것으로 실제 이직을 가장 잘 예측하는 변인이다(H. W. Lee, 2011). 현 실적으로 보육교사의 이직을 측정하는데 어려움이 있으므로, 이직과 관련된 연구는 대부분 실제 이직 대신 '이직의도'를 중 심으로 살펴보고 있다(H.-K. Lee, 2018). 보육교사의 이직의도 는 보육시설 근무환경의 질이 낮고(A.-R. Son, 2009; K. Yoon $\& \mathrm{Ji}, 2011$ ), 직무만족도가 낮으며(Choe, 2017, J.-H. Kang \& Kim, 2013), 심리적 소진이 많을수록(H. S. Choe, 2017; H. Yoo $\&$ Kwon, 2017) 높은 것으로 나타났다. 또한 원장의 리더십이 낮고(K. A. Lee \& Lee, 2012), 의사결정 참여도가 낮을 때(H. S. Kim \& Cho, 2017; J. W. Lee \& Lee, 2006) 역시 이직을 많이 고 려하는 것으로 나타났다.

특히, 이직의도에 영향을 미치는 가장 중요한 요인은 직 무스트레스로 보고되고 있다(Beak, 2014; K. N. Lee \& Kang, 2014; K.-S. Pyo \& Hwang, 2011; H. M. Yoon \& Noh, 2013). 직 무스트레스란 직장 내에서 직무환경과 관련하여 조직구성원 들이 느끼는 심리적 또는 신체적 반응으로, 조직구성원들의 긴장상태를 조장할 수 있는 모든 스트레스 요인들을 일컫는 포괄적인 개념이다(K.-C. Bae, Kim, \& Hwang, 2003). 보육교 사의 직무스트레스에 영향을 미치는 요인은 개인적 특성 요 인, 근무조건 요인, 직무관련 요인, 대인관계 요인과 심리적 요 인으로 구분할 수 있다(H. Park \& Seok, 2017). 먼저 개인적 특
성 요인은 연령, 학력, 경력 등(H. M. Yoon \& Noh, 2013)이 있 으며, 근무조건 요인은 기관 유형, 급여, 담당학급, 근무시간 (Hwang \& Bae, 2014), 사회적 지지(Song, 2012)가 있다. 직무관 련 요인으로는 직무 자체(J. Y. Lee, Ji, \& Kim, 2011), 직무만족 도(Yuh, 2016), 직무 소진(H. Yoon \& Noh, 2013)이 있으며, 대 인관계 요인으로는 동료교사와의 관계(H. Shin, Shin, \& Kim, 2016), 원장과 학부모와의 관계(Ahn, Kim, \& Ahn, 2015), 원아 와의 관계 등(S.-Y. Yoo \& Kim, 2012)이 있다.

보육교사의 직무스트레스를 줄이기 위한 방안으로 근무시 간 단축, 보조교사 투입 등 구조적 환경 개선에 대한 시도가 이 루어졌다(Korea Institute of Child Care and Education [KICCE], 2017). 하지만, 같은 근무환경에서도 심리적 요인에 따라 직 무스트레스를 느끼는 정도는 개인마다 다르며, 직무스트레스 로 인해 모든 보육교사가 이직하거나, 이직을 고려하지는 않 는다(J. Park, 2013). 선행연구에 따르면 자아탄력성(Chi \& Lee, 2012), 보육효능감(E. Lee, Noh, \& Lee, 2016), 자아존중감(Y.H. Kwon, 2013), 긍정적 정서(H. Shin et al., 2016), 삶의 질(J. Lee, Kim, \& Kim, 2017), 자기정서조절 능력이 높을수록(G.-O. $\mathrm{Kim}, 2016)$ 직무스트레스를 적게 느낀다고 보고하고 있다(H.S. Park \& Seok, 2017). 하지만 선행연구의 대부분은 스트레스 에 대처하는 심리적 자원에 대한 연구가 주를 이룰 뿐, 근본적 으로 개인이 스트레스에 대해 가지는 믿음, 즉 스트레스 마인 드셋(stress mindset)이 직무스트레스와 이직의도에 미치는 영 향에 대한 연구는 부재하다.

스트레스 마인드셋이란 개인이 스트레스의 영향에 대해 가지는 관점으로 '성장적 관점' 과 '퇴보적 관점'으로 나뉜다 (Crum, Salovey, \& Achor, 2013). '성장적 관점'을 가진 개인은 스트레스의 긍정적인 효과에 대해 어느 정도 인지하고 있으 며, 스트레스를 활용하여 성장할 수 있다고 여긴다. 반면, '퇴 보적 관점'을 가진 개인은 스트레스는 무조건 부정적인 효과 를 가져 오기 때문에 피해야 한다고 여긴다. 예를 들면, 스트레 스에 대한 성장적 관점을 가진 사람의 경우 스트레스를 경험 하는 것은 건강과 활력을 향상시키며, 배움과 성장을 촉진하 고, 수행과 생산성을 높인다고 평가하지만(Crum et al., 2013), '퇴보적 관점'을 가진 개인은 스트레스를 경험하는 것은 건강 과 활력을 떨어뜨리며, 배움과 성장을 저해함과 동시에, 수 행과 생산성을 떨어뜨린다고 평가한다(Crum et al., 2013). 스 트레스 마인드셋은 근본적으로 스트레스 대처 전략(coping strategy)과 구별된다. 스트레스 대처 전략은 주로 스트레스는 부정적이라는 고정적 시각에서 출발해 스트레스를 줄이거 나 없애려는 노력인 반면(Carver, Scheier, \& Weintraub, 1989; 
Penley, Tomaka, \& Wiebe, 2002), 스트레스 마인드셋은 스트레 스의 효과성에 대한 근본적인 신념이라는 점에서 상이하다. 따라서 스트레스 마인드셋이 대처전략을 세우는데 영향을 미 칠 순 있지만 스트레스 마인드셋 자체가 대처 전략이 될 순 없 다(Crum et al., 2013).

스트레스 마인드셋은 어떻게 발달하는가? 현재까지 스트 레스 마인드셋의 발달에 관한 연구는 부재하지만 스트레스 마인드셋의 변화, 발달에 대한 질문의 답은 인지 능력에 대한 마인드셋(theory of intelligence; Dweck \& Legget, 1988; Dweck, 2002)의 연구를 통해 유추해 볼 수 있다. 스트레스 마인드셋 과 유사하게 인지능력의 가변성에 대한 개인의 인식에도 차 이가 있다. 어떤 개인은 인지능력은 노력을 통해 변화가능하 다고 믿는 반면 어떤 사람은 인지능력은 타고난 것이라 불변 한다고 믿는다. 선행연구에 따르면 이러한 인지능력에 대한 마인드셋은 주변인들의 언어적 피드백을 통해서 영·유아기부 터 변화, 발달하며, 이후 개인적인 경험을 통해 강화될 수 있 다(Gunderson et al., 2013; Haimovitz \& Dweck, 2016; D. Park, Gunderson, Tsukayama, Levine, \& Beilock, 2016; Pomerantz \& Kempner, 2013). 예를 들어, 인지능력은 고정되어 있다고 믿는 교사일수록 학생들에게 배움보다는 높은 성적의 중요성을 더 욱 강조하였고, 이런 교사들과 1년을 보낸 학생들은 학년 말 인지능력은 고정되어 있다고 믿는 경향이 높은 것으로 나타났 다(D. Park et al., 2016). 이와 유사하게 스트레스 마인드셋 역 시 스트레스를 대하는 주변인들의 태도나 행동을 모방하면서 변화, 발달 할 수 있을 것이다.

선행연구에 따르면, 스트레스 마인드셋은 개인의 정서, 인 지, 행동에 영향을 미친다. 스트레스에 대해 성장적 관점을 가진 개인은 스트레스를 덜 느끼며, 우울감과 불안감이 낮은 반면, 에너지와 성취, 삶의 만족도는 높은 것으로 나타났다 (Crum et al., 2013, Crum \& Lyddy, 2014). 또한, 성장적 관점을 가진 학생들은 퇴보적 관점을 가진 학생들에 비해 스트레스 를 유발하는 과제(예: 대중 앞에서의 연설)를 한 후 피드백 받 는 것을 더 많이 원했고(Crum et al., 2013), 학기 초 성장적 관 점을 가진 학생일수록 부정적인 생활사건을 겪은 후 스트레 스를 덜 느끼고 자기조절 능력이 덜 낮아지는 것으로 나타났 다(D. Park et al., 2017). 더불어 업무가 과중한 상황에서도 스 트레스에 대한 성장적 관점을 가진 직원은 업무처리에 효과적 인 대처방안을 세우는 것으로 나타났다(Casper, Sonnentag, \& Tremmel, 2017).

이와 같이 국외에서는 스트레스 마인드셋 연구가 활발히 진행되고 있는 반면, 국내에서는 현재까지 1 편의 연구만 이루
어졌다. 국내 20 - 30대와 40대 직장인 328명을 대상으로 한 Y. Kim (2015)의 학위논문에 따르면, 20 - 30대에서 40대로 연 령이 증가할수록 스트레스에 대한 성장적 관점을 가지고 있 으며, 스트레스에 대한 성장적 관점을 가진 개인일수록 자아 탄력성이 높은 반면 지각된 스트레스는 낮은 것으로 나타났 다. 비록 Y. $\operatorname{Kim}$ (2015)의 학위논문이 국내에 스트레스 마인드 셋의 개념을 알리는 의미 있는 연구이긴 하나, 성인 직장인이 라는 광범위한 대상으로 연구가 이루어져, 대상자의 직업, 직 장, 직책 등 스트레스에 영향을 미치는 구체적인 정보가 부족 하다. 또한 스트레스 마인드셋이 인지적 변인인 자아탄력성에 미치는 영향에 대해서만 서술하고 있어, 이직과 같은 행동적 변인에 미치는 영향에 대해서는 알 수 없다.

이에 본 연구에서는 높은 이직률을 보이는 직업 중 하나인 보육교사를 대상으로 스트레스 마인드셋과 직무스트레스, 이 직의도와의 관계를 알아보고자 한다. 비록, 국내외 연구를 통 틀어 현재까지 스트레스 마인드셋과 이직의도 간의 관계를 탐 구한 연구는 부재하지만, 스트레스 마인드셋이 개인의 수행 능력과 생산성, 대처전략(Crum et al., 2013) 및 소진(Ben-Avi, Toker, \& Heller, 2018)에 영향을 미친다는 선행연구를 고려해 볼 때, 스트레스의 효과에 대한 개인적인 견해가 이직의도에 영향을 미칠 수 있을 것이라 유추해 볼 수 있다. 더불어 스트레 스 마인드셋이 개인이 지각하는 스트레스 정도에 영향을 미치 며(Crum et al., 2013, Y. Kim, 2015), 직장인의 직무스트레스가 이직과 상관이 있다는 선행연구(Beak, 2014; K. N. Lee \& Kang, 2014; K.-S. Pyo \& Hwang, 2011; H. M. Yoon \& Noh, 2013)를 토 대로 스트레스 마인드셋이 직무스트레스를 매개로 이직의도 를 예측할 것이라 추측해 볼 수 있다. 즉, 스트레스에 대한 성장 적 견해를 가진 교사는 조직 내에서 발생하는 직무스트레스를 덜 느끼고, 이직에 대한 욕구가 낮은 반면, 스트레스에 대한 퇴 보적 견해를 가진 교사는 같은 근무환경 속에서도 직무 스트레 스가 높아, 이직에 대한 욕구 또한 높을 것이라 예측된다.

본 연구에서 설정한 연구문제와 연구모형(Figure 1)은 다음 과 같다.

\section{연구문제 1}

보육교사의 스트레스 마인드셋, 이직의도, 직무스트레스 간 의 관계는 어떠한가?

\section{연구문제 2}

보육교사의 직무스트레스는 스트레스 마인드셋과 이직의도 와의 관계를 매개하는가? 


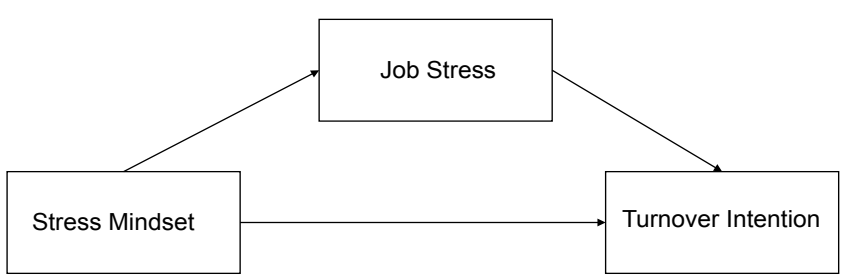

Figure 1. Path model showing the effect of stress mindset on turnover intention mediated by job stress.

\section{연구방법}

\section{연구대상}

본 연구는 1 급 보육교사 승급교육에 참여한 $\mathrm{C}$ 지역에 근무하 는 보육교사를 대상으로 하였다. 영유아보육법 시행규칙에 따르면, 1 급 보육교사 승급교육 이수 대상자는 '2급 보육교사 자격 취득 후, 보육업무 경력이 만 2년 이상이 경과한 사람이 나 보육교사 2급 자격을 취득한 후 보육 관련 대학원에서 석 사학위 이상을 취득한 경우는 보육업무 경력이 만 6개월이 경 과한 사람'이다(MOHW, 2018). 본 연구에서는 승급교육을 실 시하는 C대학교 평생교육원의 협조를 받아 1 급 보육교사 승 급교육에 참여한 보육교사에게 연구에 대해서 소개하고 자발 적으로 연구에 참여하기를 원하는 보육교사를 대상으로 편의 표집 하였다. 동의서는 승급 교육 과정 중 강사의 동의를 얻 어 배부하였고, 보육교사가 서면 작성 후 연구원이 수거하였 다. 이직의도라는 민감한 정보에 대한 설문이라는 점을 감안 하여 설문지는 동의서에 서면 동의한 보육교사 173 명에게 개 별로 스마트폰 및 이메일을 통해 온라인 설문지를 배포 후, 총 121 부가 회수 되었다. 그 중 설문지 24부(19.8\%)는 불성실하 거나 대상에 해당하지 않아 제외하고, 총 97 부(80.2\%)를 분 석하여 사용하였다. 분석에 포함된 응답자의 성별은 여자 91 명(93.8\%), 남자 6명(6.2\%)이었다. 총 교사 경력은, 3 년에서 6 년 미만이 53명(54.6\%)으로 가장 많았으며, 1년에서 3년 미만 이 41명(42.3\%), 6년에서 9년 미만이 2명(2.1\%), 12년 이상 1 명(1.0\%) 순으로 나타났다. 급여는, 150 만원 이상에서 200만 원 미만이 51명(52.6\%)으로 가장 많았으며, 100 만원 이상에서 150 만원 미만 34명(35.1\%), 200만원 이상 11 명(11.3\%) 순으로 나타났다. 어린이집 유형은, 민간어린이집 47명(48.5\%)으로 가장 많았으며, 가정어린이집 20명(20.6\%), 법인어린이집 16 명(16.5\%), 국공립 및 시립어린이집 11 명(11.3\%), 직장 어린이 집 및 기타 3 명 $(3.1 \%)$ 순으로 나타났다.
Table 1

General Characteristics of Childcare Teachers

\begin{tabular}{lc}
\hline \multicolumn{1}{c}{ Variable } & $N(\%)$ \\
\hline Gender & $91(93.8)$ \\
Female & $6(6.2)$ \\
Male & \\
Teaching experiences & $41(42.3)$ \\
1-2 years & $53(54.6)$ \\
3-5 years & $2(2.1)$ \\
6-8 years & $0(0.0)$ \\
9-11 years & $1(1.0)$ \\
More than 12 years & \\
Salary (10,000 won) & $1(1.0)$ \\
$<100$ & $34(35.1)$ \\
100-150 & $51(52.6)$ \\
151-200 & $11(11.3)$ \\
$>$ 200 & \\
Center type & $11(11.3)$ \\
Public & $47(48.5)$ \\
Private & $20(20.6)$ \\
Worke & \\
\hline
\end{tabular}

Note. $N=97$.

\section{연구도구}

$$
\text { 스트레스 마인드셋 }
$$

스트레스 마인드셋(Stress Mindset Measure, [SMM])을 측정하 기 위해 Crum 등(2013)이 개발하고 Y. Kim (2015)이 번안한 척 도를 사용하였다. 측정도구는 스트레스와 관련된 증상, 징후, 성장, 학습, 불확실성, 수행, 생산성에 대한 개인의 신념을 측 정하는 총 8문항(예: “업무 스트레스의 효과는 부정적이며 피 해야만 한다.", "업무 스트레스를 경험하는 것은 나의 배움과 성장을 촉진한다.”)이다. 총 8 문항 중 4 개의 부정적인 항목은 역채점하여 평균으로 취합하였다. SMM은 5점 리커트(Likert) 척도로 구성되어 있으며, SMM의 점수가 높을수록 스트레스 에 대한 성장적 관점이 높음을 나타낸다. 직장인을 대상으로 한 Y. Kim (2015)의 연구에서 SMM의 Cronbach's $\alpha$ 는 .85이며, 본 연구에서의 Cronbach's $\alpha$ 는 .81이다. 


\section{직무스트레스}

보육교사의 직무스트레스를 측정하기 위하여 D'Arienzo, Morraco와 Krajewski (1982)이 개발하고 H. Y. Shin (2004)이 번안, 수정한 척도를 사용하였다. 측정도구의 하위변인은 업 무 과부하 8문항(예: "보육활동을 위해 준비할 시간이 충분하 지 않다.”), 원장의 지도력 및 행정적 지원 부족 11 문항(예: “우 리 어린이집의 운영은 바람직한 보육의 실제와 맞지 않다.”, "운영과 관련된 내 제안이나 의견이 받아들여지지 않을 때 가 있다.”), 동료와의 관계 5문항(예: “어린이집에서는 각자 에게 부여된 임무를 수행하지 않는 교사들이 있다.”), 학부모 와의 관계 3문항(예: "학부모들은 교사에게 무례하거나 과도 한 요구를 한다.”)으로 총 27문항의 5점 리커트 척도로 구성 되어 있다. 점수가 높을수록 직무스트레스가 높다는 것을 뜻 한다. 보육교사를 대상으로 한 H. Y. Shin (2004)의 연구에서 Cronbach's $\alpha$ 는 업무 과부하 .79, 원장의 지도력 및 행정적 지 원 부족 .88, 동료와의 관계 .85, 학부모와의 관계 .69로 전체 .89 로 나타났으며, 본 연구에서 Cronbach's $\alpha$ 는 원장의 지도력 및 행정적 지원 부족 .86, 업무 과부하.73, 동료와의 관계 .78, 학부모와의 관계. 75 로 전체 .88 이다.

\section{이직의도}

보육교사의 이직의도를 측정하기 위하여 Allen과 Meyer (1990) 이 개발하고 Mun (2007)이 보육교사에 맞게 수정, 번안한 척 도를 사용하였다. 총 6 문항으로 이직을 위한 구체적인 계획 여부를 측정하며(예: “나는 이 직장을 그만 두고 싶다는 생각 을 한다.”), 5점 리커트 척도로 구성되어 있다. 총 점수가 높을 수록 이직의도가 높음을 의미한다. Mun (2007)의 연구에서 Cronbach's $\alpha$ 는 .91이며, 본 연구에서의 Cronbach's $\alpha$ 는 .82이다.

\section{연구절차}

자료수집과 모든 연구절차는 종합대학의 생명윤리심의위원 회의 승인을 받은 후 진행되었다. 데이터 수집은 2017년 7월 부터 8월까지 실시되었으며, C대학교의 협조를 받아 1 급 승급 교육에 참여한 보육교사에게 동의를 구하여, 수락한 보육교사 를 대상으로 동의서를 배부하여 서면작성 후 연구원이 수령하 였다. 보육교사에게 개별 스마트폰 및 이메일을 통해 온라인 설문지를 배포하였으며, 설문은 개별로 1 주일의 작성 기간을 고지하여 참여자가 원하는 시간대에 응답하도록 하였다.

\section{자료분석}

본 연구의 자료는 SPSS 22.0 와 PROCESS macro (Hayes, 2013) 를 사용하여 분석하였다. 우선 연구 대상자의 일반적 특성을 알아보기 위해 빈도와 백분율을 분석하였으며, 조사도구의 신 뢰도를 알아보고자 Cronbach's $\alpha$ 를 산출하였다. 또한 기술통 계를 통해 각 변인의 평균값과 표준편차, 범위를 산출하였으 며 스트레스 마인드셋, 직무스트레스 및 이직의도 간의 관계 를 알아보기 위해 Pearson의 상관분석을 실시하였다. 보육교 사의 스트레스 마인드셋과 이직의도와의 관계에서 직무스트 레스의 매개효과를 알아보기 위해 Baron과 Kenny (1986)의 방 법을 사용하여 분석하였으며, 간접 효과의 유의성을 알아보기 위하여 Hayes (2013)의 PROCESS macro를 활용하여 부트스트 래핑(bootstrapping)을 실시하였다.

\section{연구결과}

\section{보육교사의 스트레스 마인드셋, 직무스트레스 및 이직의도}

보육교사의 스트레스 마인드셋, 직무스트레스 및 이직의도의 평균, 표준편차, 최대, 최소 및 주요 변수 간 상관계수는 Table 2에 제시하였다. 먼저, 보육교사의 평균 스트레스 마인드셋 점수는 5점 척도에 2.31점 $(S D=0.64)$ 으로 스트레스의 부정적 효과를 긍정적 효과에 비해 많이 지각하고 있는 것으로 나타 났다. 직무스트레스는 3.36점 $(S D=0.52)$, 이직의도의 평균은 3.45 점 $(S D=0.79)$ 으로 나타났다.

스트레스 마인드셋과 직무스트레스 간에는 통계적으로 유 의미한 부적상관이 나타났다 $(r(95)=-.30, p<.01)$. 스트레스 마인드셋과 이직의도 간에도 통계적으로 유의미한 부적상관 이 나타났으며 $(r(95)=-.34, p<.01)$, 이직의도와 직무스트레 스 간에는 통계적으로 유의미한 정적상관이 나타났다 $(r(95)=$ $.43, p<.01)$.

\section{스트레스 마인드셋과 이직의도 간의 관계에 서 직무스트레스의 매개효과}

스트레스 마인드셋이 직무스트레스를 매개로 이직의도에 미 치는 영향을 알아보기 위해 Baron과 Kenny (1986)의 매개분석 방법을 사용하였다. 검증 1 단계에서 스트레스 마인드셋이 이 
Table 2

Correlation Between Stress Mindset, Job Stress, and Turnover Intention

\begin{tabular}{lccc}
\hline & Stress mindset & Job stress & Turnover intention \\
\hline Stress mindset & - & & - \\
Job stress & $-.30^{* *}$ & $.43^{* *}$ & - \\
Turnover intention & $-.34^{* *}$ & 3.36 & 3.45 \\
\hline$M$ & 2.31 & 0.52 & 0.79 \\
$S D$ & 0.64 & 1.89 & 1.00 \\
Min. & 1.00 & 4.63 & 5.00 \\
Max. & 3.88 & & \\
\hline
\end{tabular}

$* * p<.01$.

Table 3

Mediating Effect of Job Stress on the Relationship between Stress Mindset and Turnover Intention

\begin{tabular}{|c|c|c|c|c|c|c|c|}
\hline Stage & $\begin{array}{c}\text { Dependent } \\
\text { variable }\end{array}$ & $\begin{array}{c}\text { Independent } \\
\text { variable }\end{array}$ & $B(S E)$ & $\beta$ & $t$ & $R^{2}\left(\operatorname{Adj} . R^{2}\right)$ & $F$ \\
\hline 1 & Turnover intention & Stress mindset & $-0.42(0.12)$ & -0.34 & $-3.49^{* *}$ & $.11(.10)$ & $12.18^{* *}$ \\
\hline \multirow[t]{2}{*}{3} & \multirow[t]{2}{*}{ Turnover intention } & Stress mindset & $-0.28(0.12)$ & -0.23 & $-2.41^{*}$ & \multirow{2}{*}{$.23(.22)$} & \multirow{2}{*}{$14.33^{* * *}$} \\
\hline & & Job stress & $0.55(0.14)$ & 0.36 & $3.84^{* * *}$ & & \\
\hline
\end{tabular}

${ }^{*} p<.05 .{ }^{* *} p<.01 .{ }^{* * *} p<.001$.

Table 4

Bootstrapping Method Test of the Indirect Effect of Job Stress on the Relationship Between Stress Mindset and Turnover Intention

\begin{tabular}{|c|c|c|c|}
\hline \multicolumn{4}{|c|}{ Bootstrap } \\
\hline \multirow{2}{*}{ Indirect effect coefficient } & \multirow{2}{*}{ Standard error } & \multicolumn{2}{|c|}{$95 \% \mathrm{CI}$} \\
\hline & & Lower value & Upper value \\
\hline$-0.13^{*}$ & 0.06 & -0.27 & -0.03 \\
\hline
\end{tabular}

${ }^{*} p<.05$.

직의도에 미치는 영향을 유의미하게 예측하는지 측정하고, 검 증 2 단계에서는 스트레스 마인드셋이 매개변인인 직무스트 레스를 유의미하게 예측하는지 측정하였다. 그리고 검증 3 단 계에서는 스트레스 마인드셋과 직무스트레스를 함께 투입하 여 직무스트레스가 이직의도를 유의미하게 예측하는지를 살 펴보았다. 더불어 이직의도에 미치는 직무스트레스의 영향 이 여전히 유의한지, 1 단계와 비교해서 효과가 유의미하게 줄 어들었는지 살펴보았다. 간접효과의 유의성을 알아보기 위해 PROCESS macro (Hayes, 2013)를 활용하여 부트스트래핑을 실시하였다. 즉, 재추출된 표본수 5,000개를 통하여 $95 \%$ 간접 효과 계수의 신뢰구간을 확인하였으며, 신뢰구간이 0을 포함 하지 않으면 간접효과가 유의한 것으로 해석할 수 있다.

결과는 Table 3 과 같다. 1 단계에서 스트레스 마인드셋은 이 직의도에 부적으로 유의한 영향을 미치는 것으로 나타났다 $(\beta$
$=-0.34, p<.01) .2$ 단계에서 스트레스 마인드셋은 직무스트레 스에 부적으로 유의미한 영향을 미쳤다 $(\beta=-0.30, p<.01) .3$ 단 계에서 스트레스 마인드셋과 직무스트레스를 동시에 투입한 결과, 직무스트레스가 이직의도에 유의미한 영향을 미치는 것 으로 나타났다 $(\beta=0.36, p<.01)$. 더불어 스트레스 마인드셋이 이직의도에 미치는 영향력은 검증 2 단계의 회귀계수보다 감 소하였으나 여전히 통계적으로 유의하여 부분매개효과가 나 타났다 $(\beta=-0.23, p<.05)$. 부트스트래핑 결과(Table 4$)$ 는 $95 \%$ 신뢰구간에서 하한값 -.27, 상한값 -.03으로 이들 사이에 0이 포함되지 않는 것으로 나타나 간접효과가 통계적으로 유의하 다고 해석할 수 있다. 결과적으로 스트레스 마인드셋과 이직 의도 간의 관계에서 통계적으로 유의미한 직접효과와 더불어 직무스트레스를 통한 간접효과가 나타났다. 또한 본 연구 결 과의 유의 수준은 연구 대상자의 성별, 총 근무 경력, 급여, 근 
무 기관 유형을 통제하여도 변하지 않았다.

\section{논의 및 결론}

본 연구에서는 비교적 최근 소개된 스트레스 마인드셋 개념을 보육교사에게 적용해 보고, 스트레스 마인드셋과 직무스트레 스, 이직의도와의 관계를 살펴봄으로써 보육교사의 이직에 대 한 대책마련에 기초자료를 제공하고자 하였다. 본 연구의 결 과에 대한 논의는 다음과 같다.

첫째, 보육교사의 스트레스 마인드셋의 평균점수는 5점 척 도에 2.31점으로 나타났다. 우리나라 직장인을 대상으로 한 연구의 2.69점(Y. Kim, 2015), 미국 직장인을 대상으로 한 연구 의 2.55점(Crum et al., 2013)보다 낮은 점수로써 본 연구 대상 자가 스트레스의 부정적인 효과를 높게 인식하는 편임을 의 미한다. 비록 현재까지 성인을 대상으로 한 연구에서 성별과 스트레스 마인드셋의 관계를 밝힌 연구는 부재하지만, 청소 년을 대상으로 한 연구에서 여학생들이 스트레스의 부정적인 효과를 높게 인식하고 있다는 것이 밝혀진 바 있다(D. Park et al., 2017). 따라서 본 연구 대상자의 대부분(93.8\%)이 여성이 었기 때문에 스트레스 마인드셋의 점수가 선행연구보다 낮게 나왔을 것이라 사료된다. 더불어, 본 연구에서 보육교사의 직 무스트레스와 이직의도는 3.36점, 3.45점으로 동일한 척도를 사용한 $\operatorname{Han}$ (2018)의 직무스트레스 2.65점과 이직의도 2.33 점, Pang (2015)의 직무스트레스 3.07점과 이직의도 2.56점 보 다 높은 것으로 나타났다. 이러한 결과는 보육교사의 경력이 낮을수록 이직의도와 직무스트레스가 높다는 선행연구(S. H. Bae, Kim, \& Han, 2014; Muchinsky \& Tuttle, 1979; H. S. Kim, 2015)에 비추어 볼 때, 본 연구 참가자들이 선행연구 참가자들 보다 경력이 적기 때문인 것으로 사료된다.

둘째, 보육교사의 스트레스 마인드셋은 이직의도와 부적 인 상관이 있는 것으로 나타났다. 이는 스트레스 마인드셋이 개인이 심리적 적응을 넘어 실제 삶과 행동에 까지 영향을 미 칠수 있음을 의미한다. 비록 현재까지 스트레스 마인드 셋이 개인의 실제 행동에까지 영향을 미친다는 연구는 미비하지 만, 스트레스 마인드셋이 실제 사망률을 예측한다는 연구결과 (Keller et al., 2012)에서 스트레스 마인드셋이 심리. 정서뿐 아 니라 신체적 건강, 의사결정 등 개인의 전반적인 삶에 영향을 미친다는 것을 유추해 볼 수 있다. 물론, 본 연구에서는 교사들 의 실제 이직이 아닌 이직의도를 측정했다는 점에서 제한적일 수 있으나, 이직의도가 이직을 예측하는 가장 강력한 변인이
라는 점(Bluedorn, 1982; Mobley, 1977)에서 스트레스 마인드셋 이 실제 이직까지 예측할 수 있을 것으로 보인다.

셋째, 보육교사의 스트레스 마인드셋은 직무스트레스를 매 개로 직·간접적으로 이직의도에 영향을 미치는 것으로 나타났 다. 즉, 스트레스의 긍정적인 효과를 높게 지각하는 보육교사 일수록 직무스트레스를 덜 느끼고 이직의도가 낮은 것으로 나 타났다. 이는 스트레스에 대한 성장적 관점을 가지고 있을수 록 스트레스를 덜 지각한다는 선행연구(Crum et al., 2013; Y. Kim, 2015; D. Park et al., 2017)와 일치하며, 직무스트레스가 높더라도 스트레스에 대한 성장적 관점을 가지고 있을수록 소 진이 낮아진다는 선행연구(Hahm, 2016)와도 맥을 같이한다. 즉, 스트레스 마인드셋이 과중한 업무와 열악한 업무 환경 속 에서 느끼는 직무스트레스를 감소시켜주어 궁극적으로 보육 의 연속성을 높일 수 있음을 의미한다. 더불어, 스트레스 마인 드셋이 이직의도에 직접적인 영향을 미치는 변인으로서, 보육 교사가 유사한 강도의 직무 스트레스를 경험 한다 할지라도, 스트레스에 대한 성장적 관점을 지닌 보육교사의 경우 이직을 덜 고려한다고 해석 할 수 있다.

비록 본 연구에서는 보육교사가 스트레스에 대해 가지는 관점이 유아에게 미치는 영향에 대해서 탐구하지 않았지만 보 육교사의 스트레스 마인드셋이 영유아들의 스트레스 마인드 셋 발달에도 영향을 줄 수 있을 것이라 사료된다. 보육현장에 서의 보육교사가 지닌 스트레스 마인드셋은 유아들에게 사회 적 모방을 통해 본보기가 될 수 있다. 예를 들어, $\mathrm{A}$ 반의 보육교 사는 스트레스를 긍정적인 효과성이 높다고 평가함으로서 스 트레스를 통해 배움과 성장을 촉진하고, 수행과 생산성을 높 이며 건강과 활력을 향상시킨다는 믿음을 지니고 있다고 가정 해 보자. $\mathrm{A}$ 반의 유아가 스트레스를 지각할 경우, 평소에 $\mathrm{A}$ 반 의 보육교사를 통해 관찰된 그 행동들을 모방할 가능성이 높 다. 즉, 유아는 사회 학습의 일종인 모방을 통해 $\mathrm{A}$ 반의 보육교 사에게서 스트레스를 대처하는 방식을 직접적 혹은 간접적으 로 배우고 경험하게 된다. 더불어 '성장적 관점'을 가진 보육교 사는 유아가 현재 스트레스를 받고 있을 경우, 스트레스의 압 박을 이겨내고, 잘 활용하여 성장할 것이라는 기대와 격려, 믿 음을 가짐으로서, 그 기대에 부응하는 유아의 발달을 촉진시 킬 수 있을 것이다(Babad, Inbar, \& Rosenthal, 1982).

본 연구의 제한점과 후속 연구를 위한 제언은 다음과 같다. 첫째, 본 연구가 국내외 최초로 보육교사의 스트레스 마인드 셋을 연구했다는 점에서 의의가 있지만 연구대상자가 경력 1 년 이상에서 6년 미만의 교사라는 점에서 한계를 가진다. 때문 에 본 연구결과를 다양한 경력의 보육교사에게 적용하는 것은 
주의가 필요하며, 후속연구에서는 다양한 경력의 보육교사를 대상으로 본 연구의 결과를 반복 검증할 필요가 있다.

둘째, 본 연구가 자기보고식 설문으로만 이루어졌다는 점 에서 참가자들의 응답편향성과 변인들 간의 가상적 상관관계 가 존재했을 가능성을 배제 할 수 없다. 따라서 후속연구에서 는 스트레스 호르몬인 코티솔 농도를 측정해 보거나 종단 연 구를 통해 실제 이직 여부를 추적해 보는 등 보다 객관적인 방 법으로 개인의 스트레스 정도와 이직을 측정해 볼 수 있다.

셋째, 본 연구는 변인들 간의 상관관계를 살펴본 연구라는 점에서 실험 연구를 통해 변인들 간의 인과관계에 대한 반복 검증이 필요하다. 선행연구에 따르면 스트레스 마인드셋이 간 단한 처치로 변화가능하다(Crum et al., 2013). 스트레스의 긍 정적 혹은 부정적 효과를 시사하는 짧은 비디오를 시청하는 것만으로도 개인의 스트레스 마인드셋을 변화시킬 수 있으며, 이러한 처치는 개인의 정신, 신체적 건강과 직장에서의 생산 성에 영향을 미치는 것으로 나타났다. 이러한 선행연구를 토 대로 후속 연구에서는 국내 실정에 맞는 교육프로그램을 개발 하여, 스트레스 마인드셋, 직무스트레스, 이직의도간의 인과 관계를 탐구할 수 있다.

이러한 제한점에도 불구하고 본 논문은 이론적, 실제적 의 의를 갖는다. 본 연구는 스트레스와 마인드셋이라는 각기 다 른 두 분야의 연구를 접목하여 다학문적인(interdisciplinary) 새 로운 연구방향을 제시하였다. 또한, 스트레스 마인드셋 개념 이 일반 직업군뿐 아니라 직무 스트레스가 높다고 알려진 보 육교사에게도 적용될 수 있다는 것을 밝힘으로써 스트레스 마 인드셋 개념의 지평을 넓혔다는 점에서 이론적 의의가 있다. 더불어, 비교적 쉽게 변화 가능한 스트레스 마인드셋과 이직 의도와의 관계를 탐구하면서 실제로 보육교사 이직을 낮출 수 있는 방법을 모색하였다는 점에서 실제적인 의의가 있다. 최 근, 인지능력(theory of intelligence), 성격(theory of personality) 을 주제로 한 마인드셋 연구의 동향을 살펴보면, 마인드셋의 효과를 알리는데 그치지 않고, 실제 현장에서도 적용 가능한 개입 프로그램을 개발하는 것에 중점을 두고 있다(Paunesku et al., 2015; Walton, 2014; Yeager et al., 2014; Yeager et al., 2016). 앞서 언급한 바와 같이 스트레스 마인드셋이 간단한 영상시청 과 과거의 경험을 회상해 보는 경험을 통해 변화될 수 있다는 선행연구(Ben-Avi et al., 2018; Crum et al., 2013)를 토대로 보육 교사를 대상으로 한 스트레스 마인드셋 프로그램의 개발은 실 제 현장에서도 적용 가능한 파급력 있는 모형개발에 기초자료 로 활용될 수 있을 것으로 간주된다.

\section{Conflict of Interest}

No potential conflict of interest relevant to this article was reported.

\section{References}

\section{In English}

Allen, N. J., \& Meyer, J. P. (1990). The measurement and antecedents of affective, continuance and normative commitment to the organization. Journal of Occupational Psychology, 63(1), 1-18. doi:10.1111/j.2044-8325.1990. tb00506.x

Babad, E. Y., Inbar, J., \& Rosenthal, R. (1982). Pygmalion, galatea, and the golem: investigations of biased and unbiased teachers. Journal of Educational Psychology, 74(4), 459474. doi:10.1037/0022-0663.74.4.459

Baron, R. M., \& Kenny, D. A. (1986). The moderator-mediator variable distinction in social psychological research: Conceptual, strategic, and statistical considerations. Journal of Personality and Social Psychology, 51(6), 1173-1182. doi:10.1037//0022-3514.51.6.1173

Ben-Avi, N., Toker, S., \& Heller, D. (2018). "If stress is good for me, it's probably good for you too": Stress mindset and judgment of others' strain. Journal of Experimental Social Psychology, 74, 98-110. doi:10.1016/j.jesp.2017.09.002

Bluedorn, A. C. (1982). A unified model of turnover from organizations. Human Relations, 35(2), 135-153. doi:10.1177/001872678203500204

Carver, C. S., Scheier, M. F., \& Weintraub, J. K. (1989). Assessing coping strategies: A theoretically based approach. Journal of Personality and Social Psychology, 56(2), 267-283. doi:10.1037/0022-3514.56.2.267

Casper, A., Sonnentag, S., \& Tremmel, S. (2017). Mindset matters: The role of employees' stress mindset for day-specific reactions to workload anticipation. European Journal of Work and Organizational Psychology, 26(6), 798-810. doi:10.1080/ 1359432X.2017.1374947

Cassidy, D. J., Lower, J. K., Kintner-Duffy, V. L., Hegde, A. V., \& Shim, J. (2011). The day-to-day reality of teacher turnover in preschool classrooms: An analysis of classroom context and teacher, director, and parent perspectives. Journal of Research in Childhood Education, 25(1), 1-23. doi:10.1080/ 02568543.2011 .533118

Crum, A., \& Lyddy, C. (2014). De-stressing stress: The power of mindsets and the art of stressing mindfully. In A. le, C. 
T. Ngnoumen, \& E. J. Langer (Eds.), The Wiley Blackwell handbook of mindfulness (pp. 948-963). Hoboken, NJ: Wiley.

Crum, A. J., Salovey, P., \& Achor, S. (2013). Rethinking stress: The role of mindsets in determining the stress response. Journal of Personality and Social Psychology, 104(4), 716733. doi:10.1037/a0031201

Dweck, C. S. (2002). The development of ability conceptions. In A. Wigfield, \& J. S. Eccles (Eds.), Development of achievement motivation. San Diego: Academic Press.

Dweck, C. S., \& Leggett, E. L. (1988). A social-cognitive approach to motivation and personality. Psychological Review, 95(2), 256. doi:10.1037/0033-295X.95.2.256

D’Arienzo, R. V., Moracco, J. C., \& Krajewski, R. J. (1982). Stress in teaching: A comparison of perceived occupational stress factors between special education and regular classroom teachers. Lanham, MD: Rowman \& Littlefield.

Gunderson, E. A., Gripshover, S. J., Romero, C., Dweck, C. S., Goldin-Meadow, S., \& Levine, S. C. (2013). Parent praise to 1-to 3-year-olds predicts children's motivational frameworks 5 years later. Child Development, 84(5), 15261541. doi:10.1111/cdev.12064

Haimovitz, K., \& Dweck, C. S. (2016). Parents' views of failure predict children's fixed and growth intelligence mind-sets. Psychological Science, 27(6), 859-869. doi:10.1177/0956797616639727

Hayes, A. F. (2013). Introduction to mediation, moderation, and conditional process analysis: A regression-based approach. New York: The Guilford Press.

Hahm, S. (2016). Effect of general/job stress mindset to decrease the influence of job stress to burnout. International information institute (Tokyo). Information, 19(11B), 53655372.

Keller, A., Litzelman, K., Wisk, L. E., Maddox, T., Cheng, E. R., Creswell, P. D., \& Witt, W. P. (2012). Does the perception that stress affects health matter? The association with health and mortality. Health Psychology, 31(5), 677-684. doi: $10.1037 / \mathrm{a} 0026743$

Mobley, W. H. (1977). Intermediate linkages in the relationship between job satisfaction and employee turnover. Journal of Applied Psychology, 62(2), 237-240. doi:10.1037/00219010.62.2.237

Muchinsky, P. M., \& Tuttle, M. L. (1979). Employee turnover: An empirical and methodological assessment. Journal of Vocational Behavior, 14(1), 43-77. doi:10.1016/00018791(79)90049-6

Park, D., Gunderson, E. A., Tsukayama, E., Levine, S. C., \& Beilock, S. L. (2016). Young children's motivational frameworks and math achievement: Relation to teacherreported instructional practices, but not teacher theory of intelligence. Journal of Educational Psychology, 108(3), 300313. doi:10.1037/edu0000064

Park, D., Yu, A., Metz, S., Tsukayama, E., Crum, A., \& Duckworth, A. L. (2017). Beliefs about stress attenuate the relation adverse life events, perceived distress, and selfcontrol. Child Development. doi:10.1111/cdev.12946

Paunesku, D., Waltion, G. M., Romero, C., Smith, E. N., Yeager, D. S., \& Dweck, C. S. (2015). Mind-set interventions are a scalable treatment for academic underachievement. Psychological Science, 26(6), 784-793. doi: 10.1177/0956797615571017

Penley, J. A., Tomaka, J., \& Wiebe, J. S. (2002). The association of coping to physical and psychological health outcomes: a meta-analytic review. Journal of Behavioral Medicine, 25(6), 551-603. doi:10.1023/A:1020641400589

Pomerantz, E. M., \& Kempner, S. G. (2013). Mothers' daily person and process praise: Implications for children's theory of intelligence and motivation. Developmental Psychology, 49(11), 2040-2046. doi:10.1037/a0031840

Whitebook, M., \& Sakai, L. (2003). Turnover begets turnover: An examination of job and occupational instability among child care center staff. Early Childhood Research Quarterly, 18(3), 273-293. doi:10.1016/s0885-2006(03)00040-1

Walton, G. M. (2014). The new science of wise psychological interventions. Current Directions in Psychological Science, 23(1), 73-82. doi:10.1177/0963721413512856

Yeager, D. S., Johnson, R., Spitzer, B. J., Trzesniewski, K. H., Powers, J., \& Dweck, C. S. (2014). The far-reaching effects of believing people can change: Implicit theories of personality shape stress, health, and achievement during adolescence. Journal of Personality and Social Psychology, 106(6), 867-884. doi:10.1037/a0036335

Yeager, D. S., Romero, C., Paunesku, D., Hulleman, C. S., Schneider, B., Hinojosa, C., \& Trott, J. (2016). Using design thinking to improve psychological interventions: The case of the growth mindset during the transition to high school. Journal of Educational Psychology, 108(3), 374391. doi:10.1037/edu0000098

\section{In Korean}

Ahn, N. R., Kim, H. S., \& Ahn, S. H. (2015). The relationship between job stress and turnover intention of child care teachers and the moderating role of motivation for child care work. Journal of Korean Home Management Association, 33(5), 87-102. doi:10.7466/JKHMA.2015.33.5.87

Bae, K.-C., Kim, H.-C., \& Hwang, Y.-Y. (2003). Antecedent and consequent factors of travel agency employees stress. Journal of Tourism Sciences, 27(1), 221-243.

Bae, S. H., Kim, Y. H., \& Han, S. Y. (2014). Effects of job stress, ego-resilience and burnout on teacher's turnover intention. 
Journal of Early Childhood Education \& Educare Welfare, 18(1), 234-258.

Beak, Y. (2014). A study on moderating effects of personally. environmentally protective factors in the relationship between child care teachers' job stress and turnover intentions (Master's thesis). Retrieved from http://www.riss.kr/link?id= T13368246

Chi, M., \& Lee, J.-Y. (2012). The effect of emotional workers' egoresilience and stress-coping methods on their job stress. Korean Journal of Child Education and Care, 12(2), 249263.

Choe, H. S. (2017). The effects of resilience, job satisfaction, and burnout on intention to leave of infant teachers in Korea. Journal of Early Childhood Education \& Educare Welfare, 21(3), 129-149.

Choi, H. (2002). A study on the parent education system for young children (Master's thesis). Retrieved from http://www.riss. $\mathrm{kr} / \mathrm{link}$ ?id=T8585046

Han, E. (2018). The influences of the empowerments and the job stresses of the nursing teachers on the intention to change the job (Master's thesis). Retrieved from http://www.riss.kr/ link?id=T14751311

Hong, K.-J. (2002). A comparative study on developing curriculum of early childhood 'educare' teachers. Korea Journal of Child Care and Education, 31, 287-325.

Huh, H.-G., \& Park, I.-S. (2010). Influence of childcare teachers' quality and work attitude on childcare quality. Korea Journal of Child Care and Education, 64, 21-41.

Hwang, J.-K., \& Bae, S.-H. (2014). Work stress and self-efficacy in different types of working conditions of child care teachers. Journal of the Korea Entertainment Industry Association, 8(2), 227-239. doi:10.21184/jkeia.2014.06.8.2.227

Kang, J.-H., \& Kim, J.-Y. (2013). Relationships between family child care teacher's job satisfaction and turnover intention. Korea Journal of Child Care and Education, 76, 121-138.

Kim, B.-N., Kwon, M.-S., Kim, G.-S., \& Han, E.-H. (2015). A study on the determinants of reuse intention of childcare facilities for infants and young children: With a focus on the quality of childcare service. Korean Journal of Local Government \& Administration Studies, 29(3), 283-304.

Kim, C.-H., Mun, S.-Y., \& Park, H.-S. (2013). A structural analysis on the affecting factors of quality of service: Focusing on quality of childcare service. Korean Journal of Local Government \& Administration Studies, 27(3), 145164.

Kim, G.-O. (2016). The effects of emotional intelligence and child care teacher's job stress on turnover intentions. The Journal of Creative Personality with MeFOT, 5(1), 5-22.

Kim, H. S. (2015). Effects of emotional intelligence and job satisfaction of child-care teachers' on the turnover intention
(Master's thesis). Retrieved fromhttp://www.riss.kr/link?id= T13800907

Kim, H. S., \& Cho, H. J. (2017). Child-care teachers' emotional labor and their turnover intention: The moderating effect of job environment. Journal of Korean Council for Children \& Rights, 21(4), 585-604. doi:10.21459/kccr.2017.21.4.585

Kim, S. J., \& Kim, J. S. (2011). Effect of childminder's educational belief \& consciousness of professionalism on the quality of child-care. Korean Journal of Parent Education, 8(2), 31-52.

Kim, Y. (2015). The relationship between ego-resilience and perceived stress among office workers : Mediational effect of stress mindset (Master's thesis). Retrieved from http://www.riss.kr/ link?id=T13669181

Korea Institute of Child Care and Education. (2017). Measures to support teachers to reinforce infant class operation (Report No. 2017-12). Seoul: KICCE

Kwon, S.-M. (2011). The effect of social support of kindergarten and preschool teachers on job stress, job satisfaction, burnout and turnover intention. The Korean Open Association for Early Childhood Education, 16(5), 313-333.

Kwon, Y.-H. (2013). The effects of organizational climate, selfesteem, and job stress on childcare teacher's life satisfaction. Korea Journal of Child Care and Education, 74, 131-151.

Lee, E., Noh, S., \& Lee, K. (2016). The structural relationships among ego-resilience, job stress, efficacy of child care and teaching and infant teachers' child care commitment. The Journal of Child Education, 25(4), 5-22. doi:10.17643/ KJCE.2016.25.4.01

Lee, H.-K. (2018). Analysis of the influence factor on the turnover intention of childcare teacher: Focused on childcare policies and work environment (Master's thesis). Retrieved from http://www.riss.kr/link?id=T14740156

Lee, H. W. (2011). The effects of organizational commitment, career commitment, and job satisfaction on turnover intention of teachers in child care centers. Journal of Early Childhood Education \& Educare Administration, 15(2), 109126.

Lee, J., Kim, S., \& Kim, J. (2017). The effects of job stress on the quality of life of married childcare teachers: The mediating effects of work-family conflict and colleague conflict. Korean Journal of Child Care and Education Policy, 11(2), 57-86.

Lee, J. W., \& Lee, S. Y. (2006). Relations between caregivers' perceptions on participation in decision-making processes and organizational/psychological factors, job satisfaction, and intention to leave. Early Childhood Education Research \& Review, 10(1), 229-250.

Lee, J. Y., Ji, M. W., \& Kim, K. H. (2011). A study on the effect of adjustment of self-leadership in the influence of job stress and job involvement of care-giving teachers on 
psychological welfare. Korean Journal of Child Education and Care, 11(1), 41-57.

Lee, K. A., \& Lee, J. Y. (2012). Influence of director's leadership type on career immersion, and turnover intention among child care teachers. Journal of the Korean Society of Child Welfare, 38, 187-210.

Lee, K. N., \& Kang, J. S. (2014). The effects of job stress, emotional intelligence and teacher efficacy on burnout among early childhood teacher. Journal of Future Early Childhood Education, 21(2), 93-112.

Lim, M.-H. (2012). Examination of the postscript of the day care center passed the evaluation and certification. Journal of School Education Research, 7(2), 77-93.

Ministry of Health and Welfare (2013). Ministry of health and welfare statistical yearbook 2013 (Report No. 11-1352000000137-10). Seoul: MOHW.

Ministry of Health and Welfare. (2016). Ministry of health and welfare statistical yearbook 2016 (Report No. 11-1352000000137-10). Seoul: MOHW.

Ministry of Health and Welfare. (2017). Boyug.yangyuge daehan sahoejeog chaegim ganghwa 'je 3 cha jungjangbi boyug gibon gyehoeg (2018 2022) balpyo[보육. 양육에 대한 사회적 책임 강화'를 위한 제 3 차 중장기보육 기본계획(2018 2022)발표]. (Press release). Retrieved December, 27, 2017 from MOHW website: http://www.mohw.go.kr/

Ministry of Health and Welfare. (2018). Guide to childcare business in 2018 (Report No. 11-1352000-000191-10). Seoul: MOHW.

Mun, M. S. (2007). A study on the relations between child-care teachers' departure intentions and their work environment and job satisfaction (Master's thesis). Retrieved from http://www. riss.kr/link?id=T11051901

Noh, E.-H. (2012). Analysis about quality of childcare environment affects job satisfaction and its burn out. Korean Journal of Child Education and Care, 12(2), 67-83.

Pang, J. (2015). The effect of job stress of child-care teachers on turnover intention: Focusing on the mediating effect of egoresilience (Master's thesis). Retrieved from http://www.riss. $\mathrm{kr} /$ link?id=T13849547

Park, H., \& Seok, S. (2017). A meta-analysis of factors related to childcare teachers' job stress. The Journal of Child Education, 26(2), 187-206. doi:10.17643/KJCE.2017.26.2.10

Park, J. (2013). Effects of job satisfaction and resilience on turnover intention of child care teachers (Master's thesis). Retrieved from http://www.riss.kr/link?id=T13156909

Pyo, K.-S., \& Hwang, Y.-Z. (2011). A study on the influence of job stress on turnover intentions of child care teachers in small and medium-sized cities - moderating effects of leadership of directors. Korea Journal of Child Care and Education, 66, 1-23.
Pyo, K.-S., \& Lee, J. (2002). Hangug yeong.yuaboyug saeobui siltaewa gaeseonbangan[한국영유아보육사업의 실태와 개선방안], Korea Journal of Child Care and Education, 31, 383-420.

Rhee, J. S. (2014). A comparative study for standards of indoor in child care center environment comfort in child care center. The Treatise on The Plastic Media, 17(4), 239-246.

Shin, H., Shin, D., \& Kim, S. (2016). Relations among the affectivity, psychological well-being and job stress as perceived by child care teachers: A focus on the mediating effect of psychological well-being. Early Childhood Education Research \& Review, 20(5), 177-200.

Shin, H. Y. (2004). Effects of teacher' job stress and belief of efficacy on the quality of teachers' interaction behaviors in child care (Master's thesis). Retrieved from http://www.riss.kr/ link?id=T9780798

So, B. M. (1998). A study on teachers' intention to leave (Master's thesis). Retrieved from http://www.riss.kr/ link?id=T7110457

Son, S.-Y., Im, G.-H., \& Nam, G.-Y. (2015). Childcare center accreditation system and a quality of childcare - with focus on school parents and staff -. Korean Journal of 21st Century Social Welfare, 12(2), 35-60.

Son, A.-R. (2009). The effect of work environment on childcare teachers' turnover intentions and job satisfaction mediated by burnout -. Korea Journal of Child Care and Education, 58, 81-101.

Song, S. H. (2012). The effects of childcare teachers' job stress on their job satisfaction: Focusing on the mediating effect of human relations. Journal of Early Childhood Education \& Educare Welfare, 16(1), 133-151.

Yoo, H. (2011). A study on the relationship between teacher efficacy, psychological well - being, and turnover intention of child care teachers (Master's thesis). Retrieved from http://www.riss. $\mathrm{kr} / \mathrm{link}$ ?id=T12509836

Yoo, H., \& Kwon, J. (2017). Structural relations among child care teachers' job stress, teacher efficacy, organizational commitment, burn-out and turnover intention. Early Childhood Education Research \& Review, 21(1), 113-132.

Yoo, S.-Y., \& Kim, E.-S. (2012). A study on the relation between the satisfaction of life, job stress and stress management of teachers in child care. Journal of Korean Council for Children \& Rights, 16(2), 367-417.

Yoon, H. M., \& Noh, P. S. (2013). Relationship of work stress, career commitment, burnout, and turnover intention among educare-teachers. Journal of the Korean Society of Child Welfare, 43, 157-184.

Yoon, K., \& Ji, K. (2011). Analysis of the turnover intentions of nursery teachers: Focusing on structural features and working conditions of Seoul-type child care Centers. 
Korean Policy Sciences Review, 15(2), 171-197.

Yuh, J. (2016). Effects of job stress, teacher efficacy, and sense of community on childcare teachers' job satisfaction. The Journal of Korea Open Association for Early Childhood Education, 21(5), 597-618. doi:10.20437/KOAECE21-5-24
Minju Koo

Yeoul Shin

Daeun Park http://orcid.org/0000-0002-3090-7821

http://orcid.org/0000-0003-2145-8144

http://orcid.org/0000-0003-1371-9121

Received September 1, 2018

Revision received October 6, 2018

Accepted October 18, 2018 